\title{
Emulsion-Based RIR-MAPLE Deposition of Conjugated Polymers: Primary Solvent Effect and Its Implications on Organic Solar Cell Performance
}

\author{
Wangyao Ge, ${ }^{\dagger}$ Nan K. Li, ${ }^{\ddagger}$ Ryan D. McCormick, ${ }^{\dagger}$ Eli Lichtenberg, ${ }^{\dagger}$ Yaroslava G. Yingling, ${ }^{\ddagger}$ \\ and Adrienne D. Stiff-Roberts $* \dagger$ \\ †Department of Electrical and Computer Engineering, Duke University, Durham, North Carolina 27708, United States \\ ${ }^{\star}$ Department of Materials Science and Engineering, North Carolina State University, Raleigh, North Carolina 27606, United States
}

\section{Supporting Information}

\begin{abstract}
Emulsion-based, resonant infrared matrix-assisted pulsed laser evaporation (RIR-MAPLE) has been demonstrated as an alternative technique to deposit conjugated polymer films for photovoltaic applications; yet, a fundamental understanding of how the emulsion target characteristics translate into film properties and solar cell performance is unclear. Such understanding is crucial to enable the rational improvement of organic solar cell (OSC) efficiency and to realize the expected advantages of emulsionbased RIR-MAPLE for OSC fabrication. In this paper, the effect of the primary solvent used in the emulsion target is studied, both experimentally and theoretically, and it is found to determine the conjugated polymer cluster size in the emulsion as well as surface roughness and internal morphology of resulting polymer films. By using a primary solvent with low solubility-in-water and low vapor pressure, the surface roughness of deposited P3HT and PCPDTBT polymer films was reduced to $10 \mathrm{~nm}$, and the efficiency of P3HT:PC ${ }_{61} \mathrm{BM}$ OSCs was increased to 3.2\% ( 100 times higher compared to the first MAPLE OSC demonstration [Caricato, A. P.; et al. Appl. Phys. Lett. 2012, 100, 073306]). This work unveils the mechanism of polymer film formation using emulsion-based RIR-MAPLE and provides insight and direction to determine the best ways to take advantage of the emulsion target approach to control film properties for different applications.
\end{abstract}

KEYWORDS: MAPLE, emulsion target, polymer films, organic solar cells, dissipative particle dynamics

\section{INTRODUCTION}

Conjugated polymers are widely used in various thin-film-based organic electronic devices, ${ }^{2-4}$ particularly organic solar cells (OSCs), ${ }^{5}$ due to the superior conductivity compared to traditional plastics. These conjugated polymers are typically hydrophobic and have good solubility in a variety of nonpolar organic solvents, which enables solution-processed techniques for thin film deposition. ${ }^{6}$ Despite simplicity, low cost, and potential scale-up, all solution-processed deposition techniques involve wet deposition, which results in two limitations to practical applications of functional polymers. First, it is difficult to deposit blended films of polymers having different solubility characteristics, and second, the deposition of multilayer films with polymers having similar solubility characteristics is not possible without intermediate blocking layers. ${ }^{7}$ One method to address such limitations is to deposit the polymer films using vacuum-based physical vapor deposition (PVD) techniques, ${ }^{8,9}$ by which different polymers could be deposited onto substrates from separate sources and in a relatively dry state. In fact, thermal evaporation is a PVD technique that has shown great potential for organic material deposition and has been widely applied to deposit small organic molecules for organic light-emitting diodes
(OLEDs). ${ }^{10}$ Conventionally, the deposition of high molecular weight polymers using PVD techniques is challenging because the physical processes (e.g., heating, ion-bombardment, electronbeam bombardment, or laser ablation) to evaporate pure, organic materials in the gas phase can degrade the materials. This issue is especially problematic for polymer film deposition because, in contrast to small organic molecules, it is easier to break the long chains that are characteristic of polymers. In addition, polymer degradation can occur before reaching the melting point at which significant vapor pressure can be achieved for film deposition. As a result, vacuum-based deposition techniques are seldom used to fabricate devices based on functional polymer films because the device performance is strongly tied to the molecular weight of the constituent polymers, which cannot be compromised during the deposition. Thus, PVD techniques are mostly applied to deposition of thin films comprising oligomers and small organic molecules, and the PVD deposition of functional polymer films is limited.

Received: May 10, 2016

Accepted: July 14, 2016 


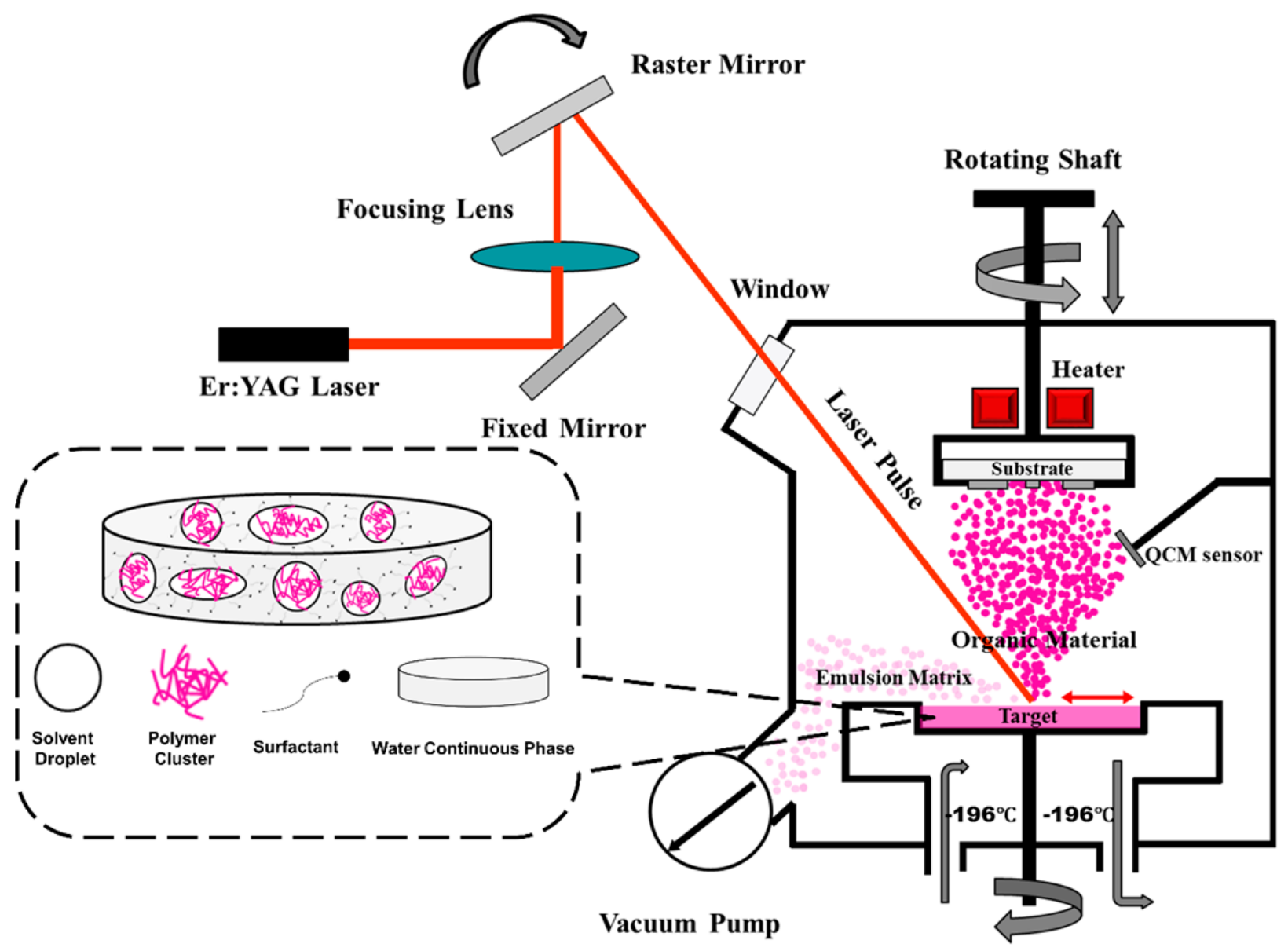

Figure 1. Schematic diagram of emulsion-based RIR-MAPLE system: an infrared Er:YAG laser pulse enters a vacuum chamber through the optical system. The laser ablates a solid frozen emulsion target with the guest organic materials (polymers) dispersed inside. The generated organic materials plume is deposited onto the substrate, whereas the emulsion host matrix is vaporized by the laser energy and pumped away. The composition and morphology of the frozen emulsion target are also shown in the zoomed figure, in which the organic solvent is dispersed as droplets in the continuous waster phase. The hydrophobic polymer only dissolves into the organic solvent and tends to aggregate into clusters that are confined inside the organic solvent droplets.

Among different PVD techniques, matrix-assisted pulsed laser evaporation (MAPLE), a variation of pulsed laser deposition (PLD), has been developed with the goal to deposit polymer thin films with minimal material degradation..$^{11-15}$ In the MAPLE deposition process, a laser, typically an ultraviolet (UV) laser, is used to ablate the target polymer, creating a vaporized plume that flushes onto the substrate to form the polymer thin film. The advantage of the MAPLE process is the incorporation of a matrix solvent in the polymer target that is vaporized by absorbing most of the laser energy and subsequently pumped away in a vacuum, leaving the polymer deposited in a dry state on the substrate. Because most of the laser energy is absorbed by the matrix solvent, as opposed to the target polymer, the photochemical degradation of the target polymer resulting from laser irradiation is minimized.

In recent years, a variation of the MAPLE technique, namely emulsion-based resonant infrared matrix-assisted pulsed laser evaporation (RIR-MAPLE), was developed ${ }^{15,16}$ with the capability to deposit different types of polymers with very little photochemical or structural degradation. ${ }^{17}$ Emulsion-based RIRMAPLE has already been applied to fabricate OSCs, ${ }^{18,19}$ optical coatings, ${ }^{20}$ and functional biosurfaces. ${ }^{21,22}$ A schematic diagram of the emulsion-based RIR-MAPLE technique is shown in Figure 1. Compared to traditional MAPLE, emulsion-based RIR-
MAPLE also combines aspects of PVD and solution-processing; yet, two important aspects of emulsion-based RIR-MAPLE stand in sharp contrast to traditional MAPLE. First, the target polymer is dispersed in the form of an emulsion with water as the main matrix to absorb laser energy. Second, instead of a UV laser, an infrared (IR) Er:YAG laser (2.94 $\mu \mathrm{m}$ peak wavelength) is used that is resonantly absorbed by any matrix component containing hydroxyl bonds $(-\mathrm{OH})$. The relatively low energy of the IR laser, and the incorporation of an emulsion matrix that shields the target polymer from incident laser irradiation, not only reduce photochemical degradation of the polymer but also maintain the polymer molecular weight after the deposition process. ${ }^{17}$

In addition to deposition of the polymer films in a dry state with minimized degradation, another advantage of emulsionbased RIR-MAPLE is the potential to control polymer film properties by engineering the composition and morphology of the emulsion target. In a typical emulsion target, the primary organic solvent is dispersed into the continuous water phase as droplets to form an oil-in-water $(\mathrm{O} / \mathrm{W})$ type of emulsion. Conjugated polymers, which are typically hydrophobic, tend to bind with organic solvents and are confined within the organic solvent droplets as polymer clusters. The hypothesis proposed in this study is that during RIR-MAPLE deposition, polymer film formation occurs by the direct transfer of these polymer clusters 
Table 1. Physical Properties of Selected Primary Solvents Including Density, Vapor Pressure, and Solubility-in-Water ${ }^{a}$

\begin{tabular}{|c|c|c|c|c|c|}
\hline \multirow[b]{2}{*}{ chemical name } & \multirow[b]{2}{*}{ density $\left(\mathrm{g} / \mathrm{cm}^{3}\right)$} & \multirow[b]{2}{*}{ vapor pressure $(\mathrm{kPa}) 25^{\circ} \mathrm{C}$} & \multirow[b]{2}{*}{ solubility-in-water $(\mathrm{g} / 100 \mathrm{~g})$} & \multicolumn{2}{|c|}{ rms rougness $(\mathrm{nm})$} \\
\hline & & & & P3HT & PCPDTBT \\
\hline toluene & 0.87 & 2.9 & 0.053 & 105.33(8.34) & 134.33(8.99) \\
\hline$o$-xylene & 0.88 & 0.93 & 0.018 & $61.97(2.11)$ & $44.10(2.65)$ \\
\hline pseudocumene & 0.88 & 0.88 & 0.0057 & $51.17(0.97)$ & $40.97(3.14)$ \\
\hline chlorobenzene & 1.1 & 1.2 & 0.0472 & 41.33(1.89) & $45.43(4.83)$ \\
\hline 1,2-dichlorobenzene & 1.3 & 0.16 & 0.0156 & $19.37(0.71)$ & $19.13(1.54)$ \\
\hline 1,2,4-trichlorobenzene & 1.5 & 0.038 & 0.00488 & $11.87(0.84)$ & $9.51(0.77)$ \\
\hline chloroform & 1.5 & 21 & 0.792 & NA & NA \\
\hline tetrahydrofuran & 0.89 & 20 & 30 & NA & NA \\
\hline
\end{tabular}

${ }^{a}$ Root-mean-square (rms) surface roughness of P3HT and PCPDTBT films deposited by emulsion-based RIR-MAPLE using these selected primary solvents are also provided. The roughness of the films was obtained by averaging three AFM images from different areas of each film. The values in parentheses are the standard deviation of the rms surface roughness for each film from three AFM images.

from the target to the substrate, and the sizes of the polymer clusters are defined by the emulsion droplet size. Therefore, the deposited polymer films are formed by the arrangement of these polymer clusters as they are transferred to the substrate in discrete packets per laser pulse. The impact of this film formation mechanism is that the size of polymer clusters and the packing between these clusters determine the surface roughness and internal morphology of the deposited polymer films as well as the resultant optical and electrical properties of the films. ${ }^{23,24}$

In previous studies, as a proof of concept demonstration, we have shown that the emulsion-based RIR-MAPLE technique is capable of fabricating bulk heterojunction OSCs. ${ }^{18}$ However, a fundamental understanding of how the emulsion target properties translate into thin film properties and OSC device performance is still unclear. Such understanding is crucial to improve the device efficiency of OSCs fabricated using RIRMAPLE, to enable the rational design of high-performance devices, and to verify the expected advantages of this PVD technique applied to polymeric materials. In this paper, the mechanism of how the primary organic solvent affects the emulsion droplet size is discussed, and the resulting impacts on the size of deposited polymer clusters and the film surface roughness are elucidated. Two commonly used conjugated polymers, poly(3-hexylthiophene-2,5-diyl) (P3HT) and poly[2,6-(4,4-bis(2-ethylhexyl)-4H-cyclopenta $\left[2,1-b ; 3,4-b^{\prime}\right]$ dithiophene)-alt-4,7(2,1,3-benzothiadiazole)] (PCPDTBT), are studied as representative material systems to determine the primary solvent effect on polymer film deposition. The corresponding OSC bulk-heterojunction active regions, P3HT:PC ${ }_{61} \mathrm{BM}$ and PCPDTBT:PC ${ }_{71} \mathrm{BM}$, are also fabricated by emulsion-based RIR-MAPLE in order to study the primary solvent effect on solar cell device performance. In order to test experimental results theoretically, dissipative particle dynamics (DPD) simulations are conducted to characterize the emulsion droplet prepared by different primary solvents, and the simulations are consistent with the observed experimental results. The conclusions of these studies provide a fundamental understanding of the polymer film formation mechanism in emulsion-based RIR-MAPLE, and they provide insight required to develop strategies for using the versatility of emulsion targets to control thin film properties and device performance in polymeric-based materials.

\section{RESULTS AND DISCUSSION}

Emulsion Target Composition and Selection of Primary Solvent. The typical emulsion composition used in emulsion-based RIR-MAPLE consists of guest polymer, primary solvent, secondary solvent, and deionized (DI) water containing surfactant. The primary solvent is used to dissolve the polymers. The secondary solvent is used to lower the overall vapor pressure of the emulsion, which could prevent the sublimation of the frozen emulsion under high vacuum and help stabilize the surface of the frozen emulsion. DI water with surfactant is used to complete the formation of the emulsion. In these studies, the primary solvent is chosen based on two families of solvents (discussed in detail later). The secondary solvent used is phenol, which has very low vapor pressure and also contains an $-\mathrm{OH}$ bond to absorb laser energy. Sodium dodecyl sulfate (SDS) is dissolved into deionized (DI) water at $0.001 \mathrm{wt} \%$ as the surfactant to improve the emulsion stability for flash-freezing. The emulsion contains the primary solvent, phenol, and DI water (with surfactant) at a volume ratio 1:0.25:3, and a total $6 \mathrm{~mL}$ emulsion is prepared for all RIR-MAPLE depositions. Considering the low volume ratio of phenol in the entire emulsion, the following analysis assumes a simplified scenario in which only the primary solvent is considered as the organic phase that participates in the formation of emulsions. In addition, the analysis assumes that the morphology of the emulsion is the same before and after the emulsion is flash frozen by liquid nitrogen on a $10-30 \mathrm{~s}$ time scale.

The guidelines to select primary solvents for this investigation followed two rules. First, the polymer must have decent solubility in the chosen primary solvents. For P3HT, PCPDTBT, and many other conjugated polymers used in OSCs, methylbenzene (known as toluene), 1,2-dimethylbenzene (known as $o$-xylene), tetrahydrofuran (THF), chloroform, chlorobenzene (CB), and 1,2-dichlorobenzene (o-DCB) are experimentally demonstrated as good solvents and are applied in the spin-casting process. Second, in order to identify which solvent property affects RIRMAPLE deposition the most, the chosen primary solvents should have properties that follow identifiable trends. Given this consideration, 1,2,4-trimethylbenzene (known as pseudocumene) and 1,2,4-trichlorobenzene (TCB) are included such that two families of solvents, alkyl aromatic solvents (toluene, $o$ xylene, pseudocumene) and chlorinated aromatic solvents (CB, $o$-DCB,TCB), with clear trends in physical properties are considered in this study. As seen in Table 1, for either solvent family, as the number of side groups increases $\left(\mathrm{CH}_{3}\right.$ - or $\mathrm{Cl}$ - for alkyl aromatic solvents and chlorinated aromatic solvents, respectively), the solvent density increases, and the vapor pressure and solubility-in-water decrease. In total, eight potential solvents are considered for the study, and the important physical parameters of each solvent are summarized in Table $1 .{ }^{25}$ Experimentally, it is found that uniform and stable emulsions 
Toluene

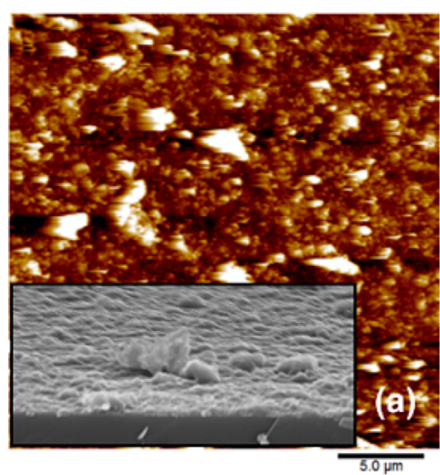

Chlorobenzene

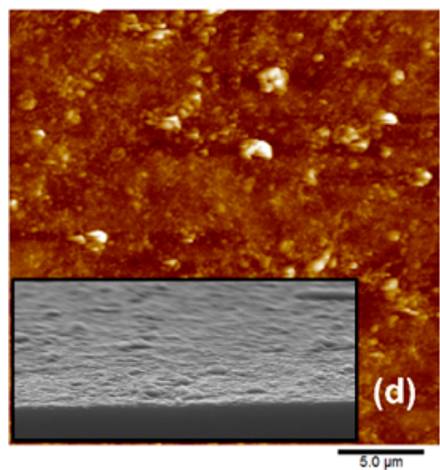

o-Xylene

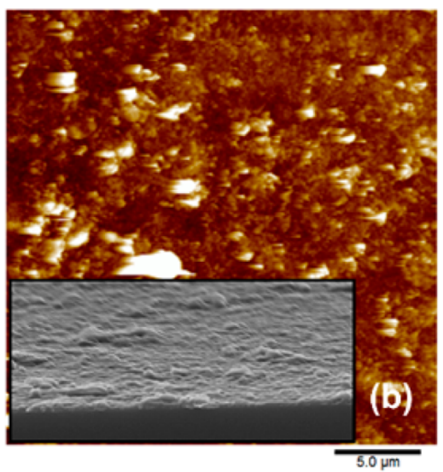

o-Dichlorobenzene

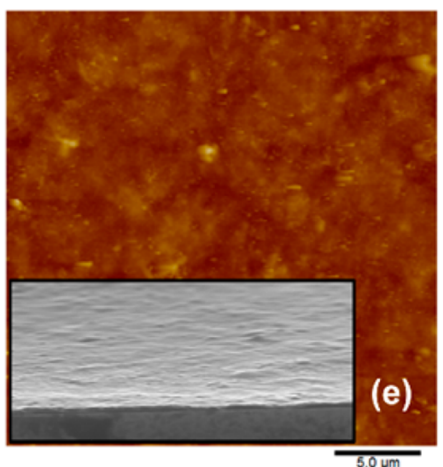

Pseudocumene

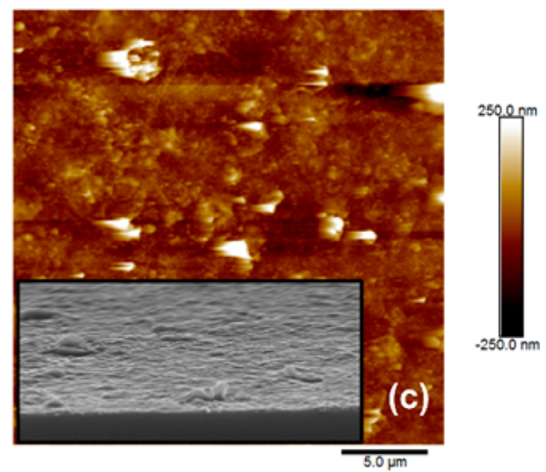

1,2,4-Trichlorobenzene

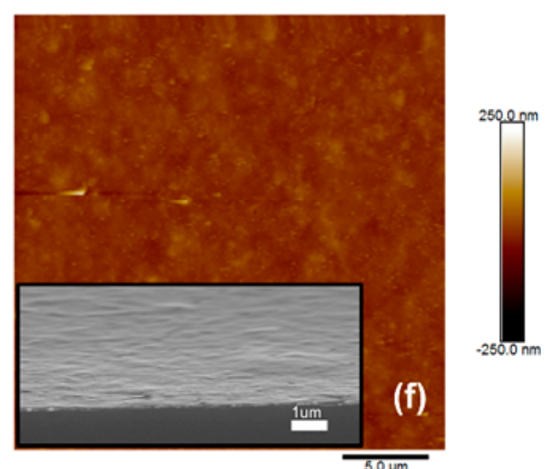

Figure 2. AFM images of P3HT films deposited from chlorinated aromatic solvents: (a) toluene, (b) $o$-xylene, (c) pseudocumene, and alkyl aromatic solvents: (d) chlorobenzene, (e) o-dichlorobenzene, (f) 1,2,4-trichlorobenzene. The inset images are the corresponding cross-sectional SEM images for the same films.

cannot be formed by using THF and chloroform as primary solvents for PCPDTBT. Hence, these two primary solvents are not included in the investigations; however, the reasons why these two solvents cannot lead to good emulsions are discussed later based on the emulsion mechanisms identified in this work.

Surface Characterization of Conjugated Polymer Films Deposited by Emulsion-Based RIR-MAPLE. One of the challenges for traditional MAPLE deposition of polymer films has been the poor surface quality. The deposited films often show nonideal surface features such as deflated balloon, ${ }^{26}$ interconnected filament, ${ }^{27}$ and elongated nanofiber. ${ }^{27}$ The overall surface is also very rough due to the presence of nanostructures, such as nanoglobulars. ${ }^{28}$ While rough films may be beneficial for some applications, such as gas sensors in which high surface area can enhance the sensitivity of detection, ${ }^{29}$ such films usually have poor electrical performance because the surface roughness increases the contact resistance to metal electrodes. In previous studies, we showed that uniform polymer films with complete coverage of the substrate can be deposited by using a frozen emulsion as the IR laser ablating target. ${ }^{15,16}$ In the same study, we also showed that the surface roughness of the deposited film can be adjusted from more than $100 \mathrm{~nm}$ to as low as $10 \mathrm{~nm}$ simply by changing the $-\mathrm{OH}$ bond concentration in the emulsion. Relatively smooth polymer films deposited by emulsion-based RIR-MAPLE are free of the abnormal surface features usually seen in UV-MAPLE deposited films. Table 1 also shows the rootmean-square (rms) surface roughness for P3HT and PCPDTBT films deposited from the two selected solvent families. The rms roughness measurements are obtained from $25 \mu \mathrm{m} \times 25 \mu \mathrm{m}$ atomic force microscopy (AFM) height images to ensure that the roughness value is from a relatively large area and can be used to represent the overall quality of the film surface. As can be seen in Table 1, for both P3HT and PCPDTBT, the films deposited from chlorinated aromatic solvents are generally smoother than films deposited from alkyl aromatic solvents (except that pseudocumene PCPDTBT film is smoother than CB PCPDTBT film). Within each family of solvents, the rms surface roughness decreases from $\mathrm{CB}$ to $o$-DCB to TCB for chlorinated aromatic solvents and decreases from toluene to xylene to pseduocumene for alkyl aromatic solvents. Figure 2 shows the AFM height images of P3HT films deposited from different primary solvents. These AFM height images reveal a general trend; that is, as the number of side groups (methyl or chlorine) on the benzene ring of the primary solvent increases (solvent solubility-in-water and vapor pressure decreases), the corresponding deposited film becomes smoother. In addition, Figure 2 shows cross-sectional scanning electron microscopy (SEM) images (slightly tilted) as insets to the corresponding AFM images. From the SEM images, very large polymer clusters (on the order of micrometer size), which correspond to bright spots in the AFM height images, are observed clearly and scattered on the rough films (e.g., toluene film). Apart from the scattered large clusters, the rest of the continuous film consists of wavy nanoscale features, resulting in a very rough film. For smooth films (e.g., o-DCB, TCB film), few large polymer clusters are observed on the films, and the films are smooth with features similar to spin-cast films. The AFM and SEM images of PCPDTBT films are in the Supporting Information (Figure S1) and reveal similar trends with respect to surface roughness and solvent family. The full size SEM images of the insets of Figure 2 and Figure $S 1$ are shown in Figures S2 and S3, respectively. It is important to note that the AFM images of Figure $2 \mathrm{a}-\mathrm{c}$ and Figure $\mathrm{S} 1 \mathrm{a}-\mathrm{c}$ show unavoidable 
(a)
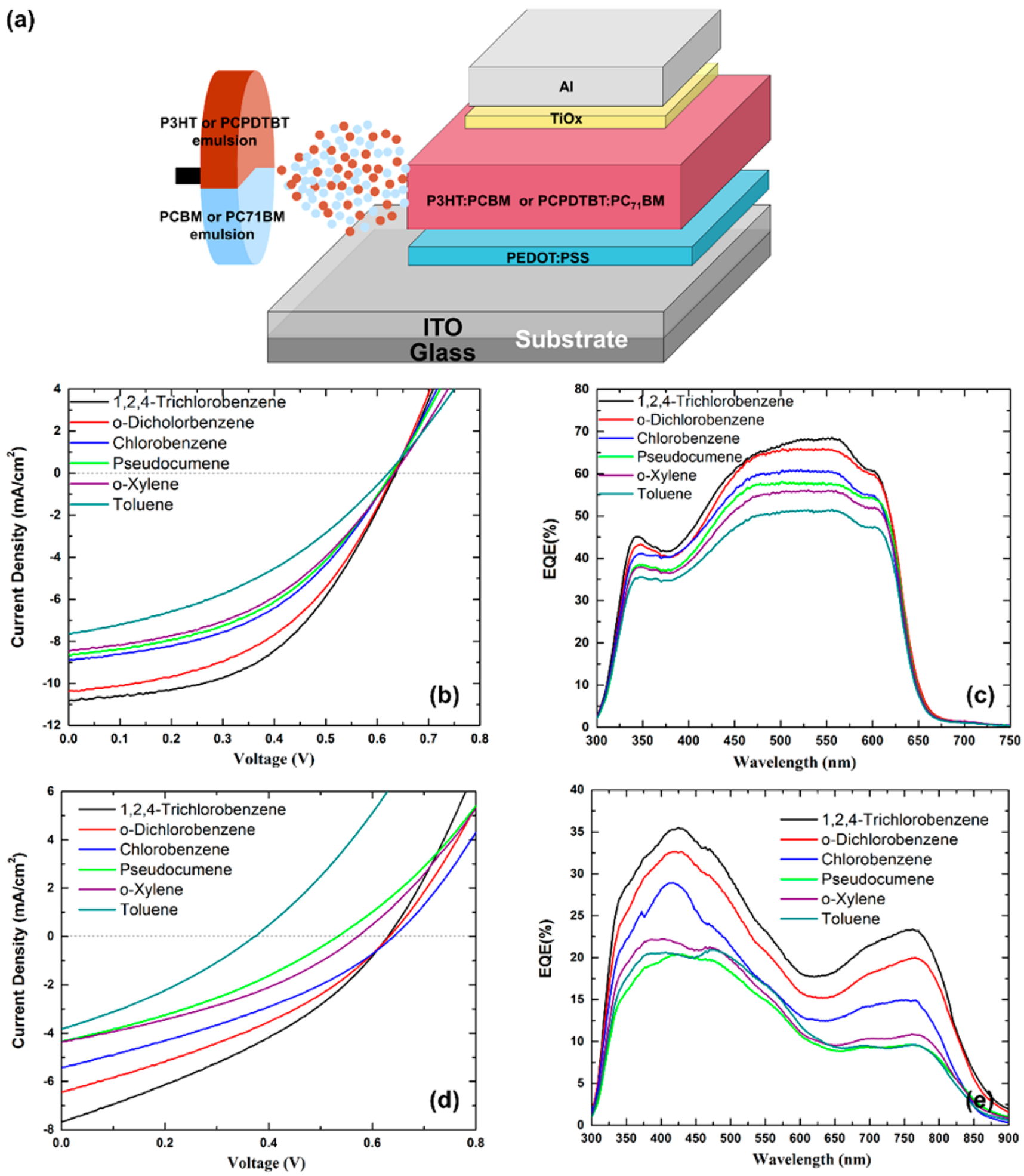

Figure 3. (a) Schematics of sequential deposition target and OSCs device configuration. Only active region is deposited by emulsion-based RIR-MAPLE using sequential deposition mode, where polymer and small organic molecules are prepared in separate emulsions and frozen in different compartments of target cup. (b) $J-V$ curves and (c) EQE spectra of P3HT:PC ${ }_{61} \mathrm{BM}$ solar cells fabricated from different primary solvents. (d) $J-V$ curves and (e) EQE spectra of PCPDTBT:PC ${ }_{71} \mathrm{BM}$ solar cells fabricated from different primary solvents.

tip artifacts due to the micrometer-sized clusters in the film. Nonetheless, the overall film surface morphology and average feature size have been determined from these images.

Bulk-Heterojunction Organic Solar Cells Fabricated by Emulsion-Based RIR-MAPLE from Different Primary Solvents. From the previous discussion, it is clear that primary solvents used in emulsion-based RIR-MAPLE have a significant impact on the surface roughness of deposited polymer films. Therefore, the primary solvents are also expected to affect the performance of OSCs based on the polymers. Because we are investigating the effect of emulsion-based RIR-MAPLE deposited polymers on OSC performance, for simplicity, only 
Table 2. Device Performance of P3HT:PC ${ }_{61} B M$ and PCPDTBT:PC 71 BM Organic Solar Cells Fabricated from Different Primary Solvents ${ }^{a}$

\begin{tabular}{|c|c|c|c|c|c|c|c|}
\hline & primary solvents & $V_{\mathrm{oc}}(\mathrm{mV})$ & $J_{\mathrm{sc}}\left(\mathrm{mA} / \mathrm{cm}^{2}\right)$ & FF (\%) & PCE (\%) & $R_{\mathrm{s}}\left(\mathrm{ohm} \mathrm{\textrm {cm } ^ { 2 } )}\right.$ & $R_{\mathrm{sh}}\left(\mathrm{ohm} \mathrm{\textrm {cm } ^ { 2 } )}\right.$ \\
\hline \multirow[t]{6}{*}{ P3HT:PC ${ }_{61} \mathrm{BM}$} & toluene & $610 \pm 9.4$ & $7.79 \pm 0.15$ & $38.7 \pm 0.6$ & $1.84 \pm 0.08$ & 24.52 & 142.86 \\
\hline & $o$-xylene & $630 \pm 3.5$ & $8.33 \pm 0.10$ & $39.3 \pm 0.6$ & $2.06 \pm 0.03$ & 21.92 & 137.40 \\
\hline & pseudocumene & $630 \pm 2.5$ & $8.58 \pm 0.15$ & $44.5 \pm 0.5$ & $2.42 \pm 0.04$ & 17.07 & 215.55 \\
\hline & chlorobenzene & $630 \pm 3.5$ & $8.85 \pm 0.03$ & $45.4 \pm 4.3$ & $2.51 \pm 0.04$ & 15.84 & 216.53 \\
\hline & $o$-dichlorobenzene & $630 \pm 2.4$ & $10.47 \pm 0.10$ & $44.8 \pm 1.4$ & $2.99 \pm 0.08$ & 12.22 & 197.05 \\
\hline & 1,2,4-trichlorobenzene & $630 \pm 4.1$ & $10.62 \pm 0.27$ & $48.8 \pm 1.1$ & $3.27 \pm 0.08$ & 14.11 & 325.26 \\
\hline \multirow[t]{6}{*}{ PCPDTBT:PC ${ }_{71} \mathrm{BM}$} & toluene & $400 \pm 18$ & $4.03 \pm 0.18$ & $32.2 \pm 0.68$ & $0.52 \pm 0.06$ & 22.68 & 108.52 \\
\hline & $o$-xylene & $560 \pm 14$ & $4.16 \pm 0.19$ & $34.5 \pm 0.94$ & $0.80 \pm 0.07$ & 31.20 & 170.38 \\
\hline & pseudocumene & $550 \pm 7.0$ & $3.96 \pm 0.29$ & $31.8 \pm 0.77$ & $0.69 \pm 0.04$ & 38.01 & 139.01 \\
\hline & chlorobenzene & $640 \pm 1.0$ & $5.20 \pm 0.34$ & $33.7 \pm 0.47$ & $1.14 \pm 0.06$ & 23.63 & 140.32 \\
\hline & $o$-dichlorobenzene & $630 \pm 7.5$ & $6.36 \pm 0.20$ & $34.9 \pm 0.43$ & $1.39 \pm 0.05$ & 15.67 & 123.17 \\
\hline & 1,2,4-trichlorobenzene & $640 \pm 4.5$ & $7.36 \pm 0.29$ & $34.2 \pm 0.38$ & $1.60 \pm 0.07$ & 16.38 & 103.50 \\
\hline
\end{tabular}

the active regions of bulk-heterojunction OSCs are deposited by emulsion-based RIR-MAPLE (i.e., blend of P3HT:PC ${ }_{61} \mathrm{BM}$ or PCPDTBT:PC $\left.{ }_{71} \mathrm{BM}\right)$. Other OSC device layers are deposited by spin-casting for convenience. The emulsion-based RIR-MAPLE deposition of the bulk heterojunction active regions is conducted in the sequential deposition mode, where the polymer (P3HT or PCPDTBT) and small organic molecules $\left(\mathrm{PC}_{61} \mathrm{BM}\right.$ or $\left.\mathrm{PC}_{71} \mathrm{BM}\right)$ are prepared in separate emulsions and are frozen into different compartments of the target cup (Figure 3a). Because this study only focuses on polymer deposition, the primary solvent in the emulsion of small organic molecules, $\mathrm{PC}_{61} \mathrm{BM}$ and $\mathrm{PC}_{71} \mathrm{BM}$, is the same for all RIR-MAPLE depositions (o-DCB). The primary solvent for the polymer emulsion, P3HT and PCPDTBT, is varied among the selected primary solvents, and this effect on polymer film properties and device performance is considered. It should be noted that the surface roughness of blended films falls between the roughness values of pure polymer films and pure small organic molecule films, which are smoother than polymer films due to the short chain length (Figure S4). The primary solvent effect on the surface roughness of small organic molecule films deposited by emulsion-based RIR-MAPLE is similar to its effect on polymer films described in this section, but much less pronounced (Figure S5).

The OSCs are based on a standard device structure, without state-of-the-art hole/electron transport layers, denoted as ITO/ PEDOT:PSS/P3HT:PC ${ }_{61} \mathrm{BM}\left(\mathrm{PCPDTBT}: \mathrm{PC}_{71} \mathrm{BM}\right) / \mathrm{TiO}_{x} / \mathrm{Al}$ and shown in Figure $3 \mathrm{a}$. The ratio of P3HT:PC ${ }_{61} \mathrm{BM}$ and PCPDTBT:PC ${ }_{71} \mathrm{BM}$ was optimized as $1.5: 1$ and 1:1.5, respectively, by the split target ratio (see Methods section). These donor:acceptor ratios were the same for all the OSCs fabricated from different selected primary solvents. A very thin $\mathrm{TiO}_{x}$ layer $(15 \mathrm{~nm})$ is spin-cast between the active region and $\mathrm{Al}$ cathode to act as (1) an optical spacer layer to enhance the absorption of the light in the active region and (2) a passivation layer to prevent the inclusion of oxygen and moisture into the film. ${ }^{30}$

Table 2 shows the OSC performance for both the P3HT:PC ${ }_{61} \mathrm{BM}$ and PCPDTBT: $\mathrm{PC}_{71} \mathrm{BM}$ material systems. As can be seen, for P3HT:PC ${ }_{61} \mathrm{BM}$ OSCs, the power conversion efficiency (PCE) is highest for the TCB solvent at $3.27 \%$, and the PCE decreases following the same solvent trend for increasing film surface roughness (decreasing PCE for $o$-DCB, CB, pseudocumene, $o$-xylene, and toluene). This trend indicates that smoother films yield better device performance, as determined by increased short-circuit current density and increased fill factor (FF) (Figure 3b). The open-circuit voltage does not vary significantly with solvent choice in the P3HT: $\mathrm{PC}_{61} \mathrm{BM}$ material system, indicating that the interfacial film morphology is essentially unchanged for different emulsion targets. The EQE (Figure 3c) shows that the increasing current density for smoother films corresponds to enhanced photon to electron conversion across the entire P3HT absorption spectrum. Given that the film composition is the same for each solvent, the primary reason for more efficient photon to electron conversion in smoother films is the improved collection of free charge carriers. Although this PCE (3.27\%) for the P3HT: $\mathrm{PC}_{61} \mathrm{BM}$ OSCs deposited using TCB is lower than reported device performance in spin-cast OSCs with the same device configuration $(5.0 \%){ }^{30}$ the device performance almost quadruples the efficiency of previously reported OSCs fabricated by emulsion-based RIR-MAPLE (0.76\%). ${ }^{31}$

For PCPDTBT:PC ${ }_{71} \mathrm{BM}$ OSCs, a similar correlation is observed between increasing device efficiency and decreasing film surface roughness as a function of primary solvent. However, in contrast to the more crystalline P3HT:PC ${ }_{61} \mathrm{BM}$ bulk heterojunction that shows a singular dependence on surface roughness, the PCPDTBT:PC ${ }_{71} \mathrm{BM}$ material system with bulkier side chains demonstrates greater variation with solvent choice. More specifically, the PCPDTBT:PC ${ }_{71} \mathrm{BM}$ OSCs demonstrate different device characteristics for the two solvent families. As an example, while the surface roughness of the CB-deposited PCPDTBT film is similar to the pseudocumene and $o$-xylene films (between 40 and $45 \mathrm{~nm}$, given the error bar), the performance of the $\mathrm{CB}$ OSC is better than the other two. In general, for the OSCs fabricated using the alkyl aromatic solvent family, the open circuit voltage, short circuit current density, FF, and PCE are optimized when $o$-xylene is used as the primary solvent (Figure $3 \mathrm{~d}$ ). The open circuit voltage demonstrates a stronger dependence on the primary solvent than the short circuit current density, indicating that the interfacial film morphology is varying with the solvent choice. In contrast, for the chlorinated aromatic solvent family, the open circuit voltage remains relatively constant, while the short circuit current density, FF, and PCE increase for solvents that decrease the surface roughness (Figure $3 \mathrm{~d}$ ). This is similar to the behavior observed for all solvents in the P3HT:PC ${ }_{61} \mathrm{BM}$ material system. The EQE (Figure 3e) shows that for the alkyl aromatic solvent family the spectral characteristics vary with the solvent choice and resulting internal morphology, while the collection of free charge carriers is essentially the same. In contrast, for the 


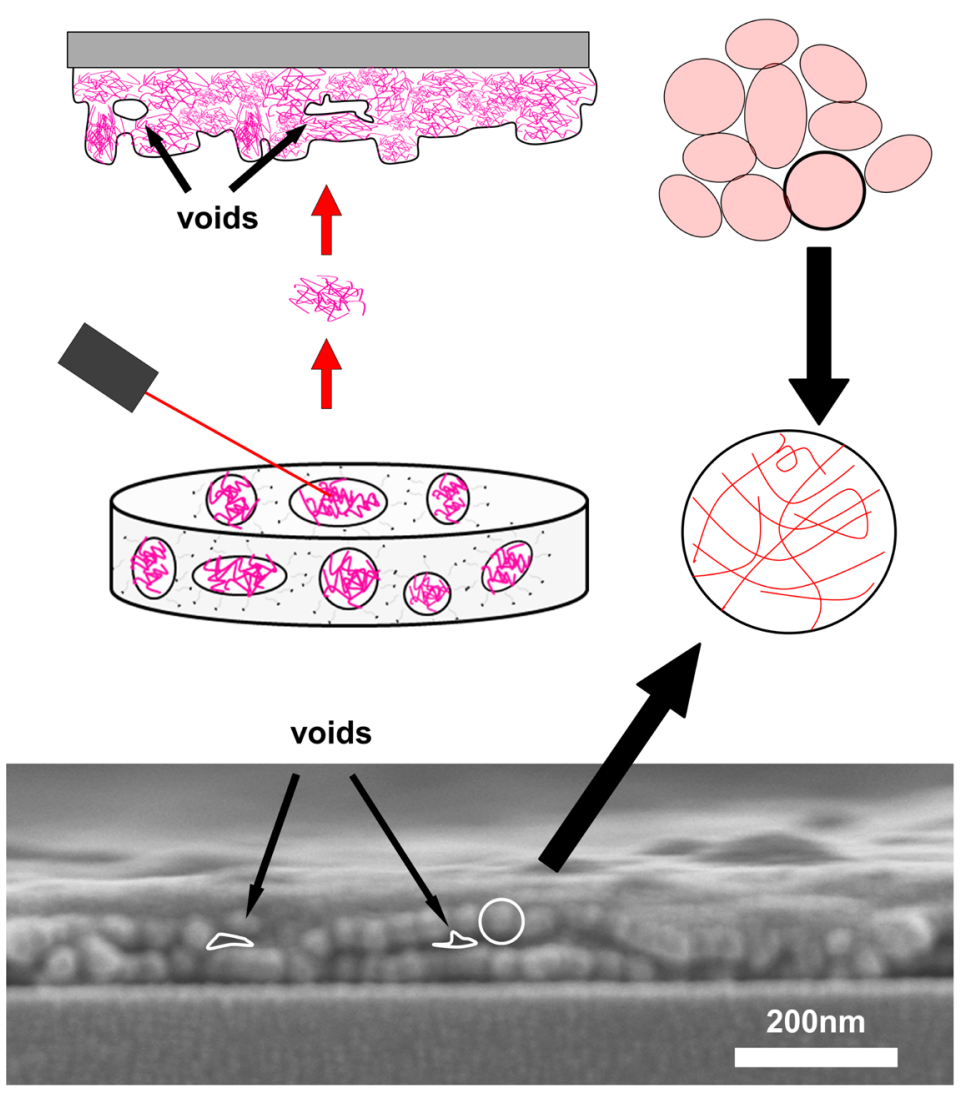

(a)
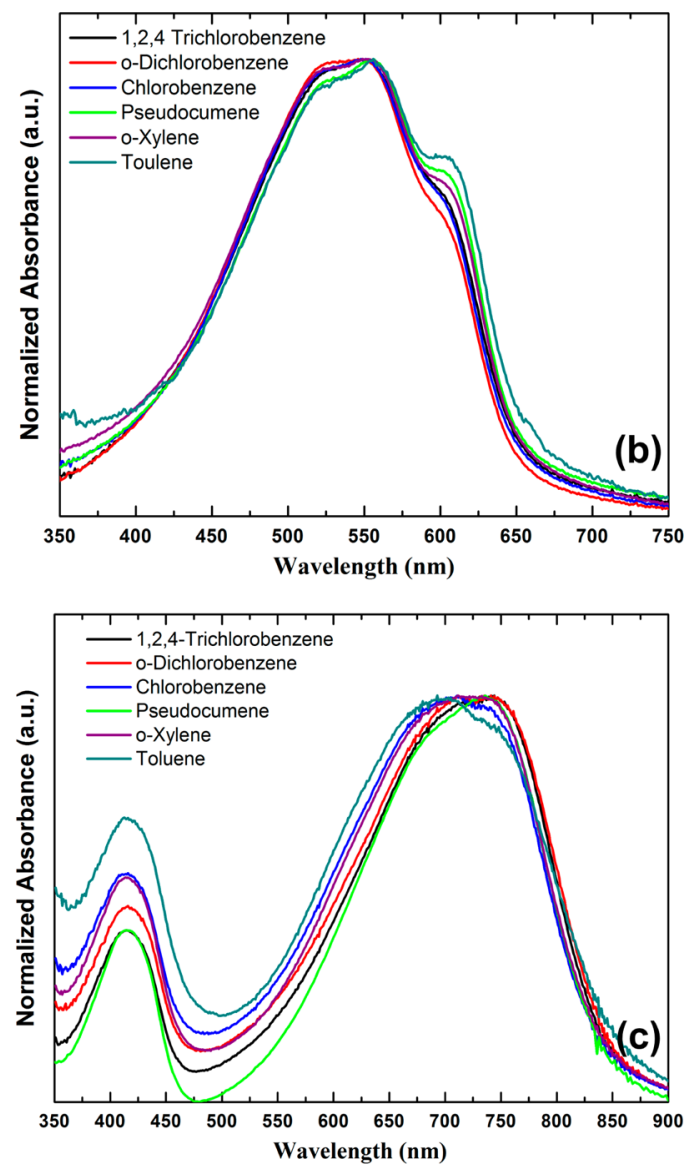

Figure 4. (a) Schematic illustrations of the film formation mechanism and the two scales of order present for polymer packing in films deposited by emulsion-based RIR-MAPLE. The surface roughness and internal voids of the illustrated film are highlighted by blackline. A cross-sectional SEM image of an RIR-MAPLE deposited polymer film (PCPDTBT deposited from $o$-DCB) shows the presence of polymer clusters and voids highlighted by white line. (b) UV-vis absorbance spectrum of P3HT films deposited from different primary solvents. (c) UV-vis absorbance spectrum of PCPDTBT films deposited from different primary solvents.

chlorinated aromatic solvent family, the short-circuit current density increases because the photon to electron conversion efficiency is higher in smoother films due to improved collection of free charge carriers.

To explain why OSCs featuring the same device configuration and fabrication process (except for the primary solvent choice) perform differently, we consider the film surface roughness and internal morphology. Large surface roughness increases the device contact resistance, which reduces the fill factor of the solar cell due to increased series resistance. For extremely large series resistance values, the short-circuit current density can even decrease. Thus, the impact of film surface roughness on the OSC device performance is very straightforward. On the other hand, the film internal morphology could affect all aspects of solar cell performance, making interpretation of the device results more complex. As seen earlier in the EQE spectra, minor changes in the spectral characteristics and more significant changes in charge transport depend on polymer chain packing and chain interactions that are determined by the internal morphology of the film for different primary solvents.

It should be noted that while the solar cell performance of emulsion-based RIR-MAPLE deposited PCPDTBT:PC ${ }_{71} B M$ OSCs is far below the reported spin-cast counterparts, ${ }^{32}$ a solvent additive such as DIO is not added during the deposition to increase the crystallinity of PCPDTBT. Although solvent additives have been demonstrated to improve OSCs perform- ance significantly in solution-processed films, ${ }^{32,33}$ it is actually found to deteriorate the performance for OSCs fabricated using emulsion-based RIR-MAPLE (Figure S6). In fact, it is not surprising that a solvent additive, like DIO, deteriorates OSC performance due to the fundamental differences in film formation and morphology for solution-processing and emulsion-based RIR-MAPLE. This discrepancy between the impacts of solvent additives is very interesting and drives further studies to better understand emulsion-based RIR-MAPLE processing.

Mechanism of Polymer Film Formation in EmulsionBased RIR-MAPLE Process. In order to better understand the internal film morphology that results from emulsion-based RIRMAPLE, we seek to elucidate the film formation mechanism. In spin-cast films, film surface roughness and film internal morphology are not directly related; that is, the surface roughness is typically low, and the film internal morphology varies depending on different processing steps. In contrast, as discussed in the previous section, for films deposited by emulsion-based RIR-MAPLE, the film surface roughness and internal morphology are directly related due to the fundamentally different mechanism of film formation.

To understand polymer film formation in RIR-MAPLE process, it is important to examine the nature of polymer molecules in the emulsion. The target emulsion that is frozen for RIR-MAPLE deposition is an oil-in-water (o/w) emulsion in 

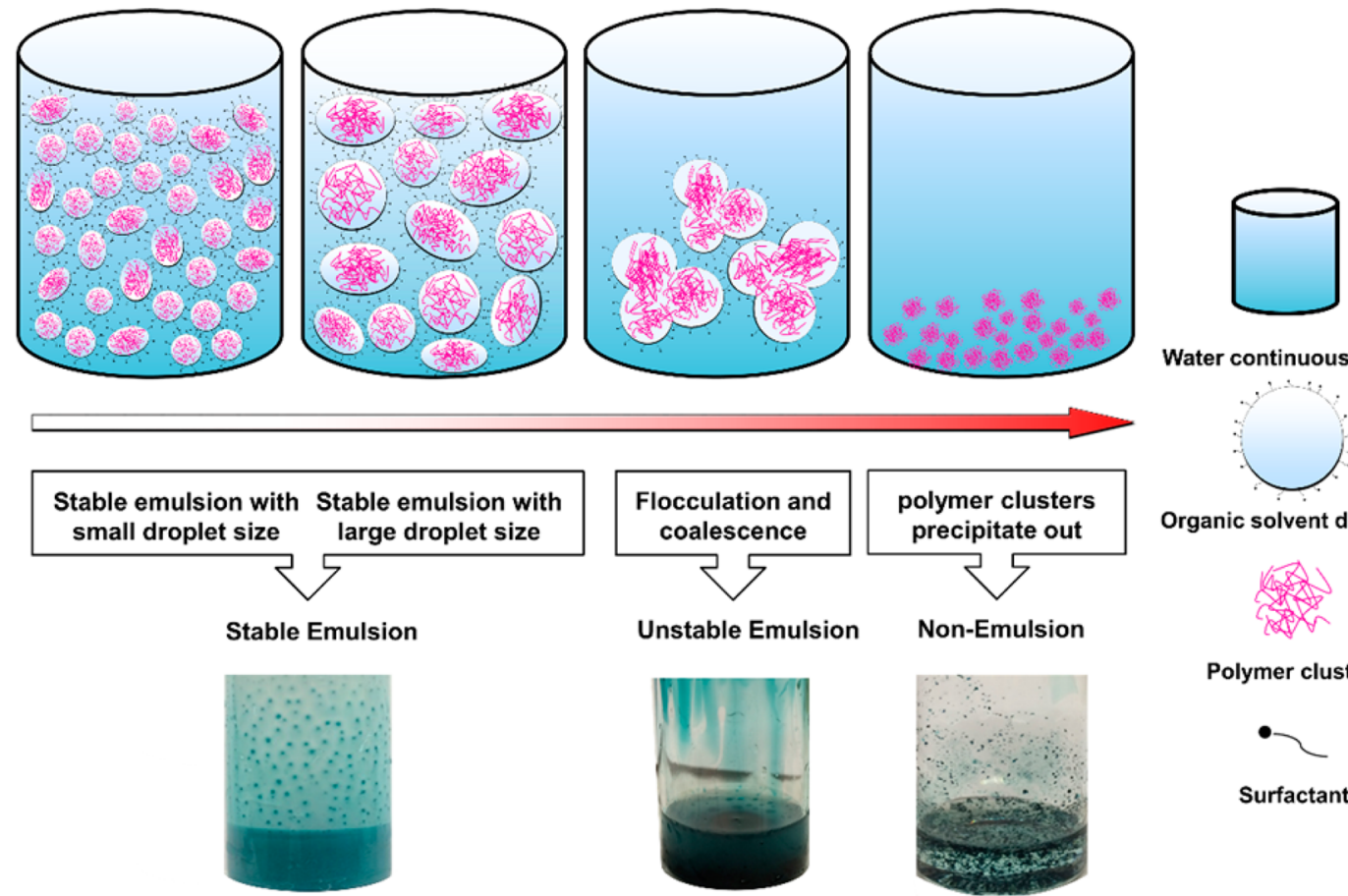

Water continuous phase

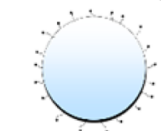

Organic solvent droplets

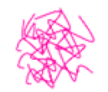

Polymer clusters

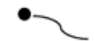

Surfactants

Figure 5. Schematic representation of different emulsions formed by using solvents with different solubility-in-water characteristics. The transition of a good, metastable emulsion (TCB emulsion), to an unstable emulsion (chloroform emulsion), to a nonemulsion (THF emulsion) is shown from left to right by both schematic representations and real pictures.

which the organic liquid phase (primary solvent) is uniformly dispersed as droplets in the continuous water phase. The conjugated polymer, which only dissolves into the organic primary solvent, is also dispersed in the continuous water phase as clusters confined inside the solvent droplets. During deposition, the water ice matrix of the emulsion absorbs the laser energy, evaporates, and is pumped away, leaving the polymer to be deposited on the substrate as discrete packets of the polymer clusters. As a result, the deposited film is constructed discretely and randomly by the stacking of these polymer clusters. In addition, these polymer clusters are likely to have different shapes and sizes; therefore, the stacked clusters are not likely to exhibit close packing. As a result, the film surface will be uneven and inherently rough, with surface features corresponding to the cluster size. In addition, the packed clusters should create voids inside the film, as depicted in Figure 4a. To support this hypothesis, a cross-sectional SEM image of a PCPDTBT film deposited from $o$-DCB by emulsion-based RIR-MAPLE is shown in Figure $4 \mathrm{a}$, from which the polymer clusters and voids can be identified.

The distinct film formation mechanism in RIR-MAPLE relates film surface roughness to the film internal morphology, all of which depend upon the polymer cluster size and emulsion droplet size. As the polymer cluster size becomes smaller, the resulting film surface becomes smoother, and polymer clusters are more tightly packed with smaller voids. The scenario for large polymer clusters is the opposite, where undesired polymer clusters are deposited on the film surface, increasing the roughness and leading to large voids inside the film with loose packing. We have used acoustic AFM techniques to characterize the stiffness of PCPDTBT films deposited from chlorinated solvents. The results in Table $S 1$ indicate that the smooth film (such as the film deposited from TCB) is also stiffer than the rough films due to more closely packed clusters in the smooth film. In terms of OSC performance, large voids could decrease the solar cell shunt resistance and reduce the open circuit voltage, which appears to be a more serious issue for noncrystalline polymers like PCPDTBT. It is also important to note that PCPDTBT devices have lower fill factors that yield less accurate fitting for the series and shunt resistances shown in Table 2.

The presence of voids in the polymer film is only one aspect of internal morphology resulting from deposition by RIR-MAPLE. In fact, the internal morphology of the polymer film can be seen as comprising two different orders of packing (Figure $4 \mathrm{a}$ ): the packing of polymer chains inside the polymer clusters and the packing among the polymer clusters. While the voids in the film are mainly determined by packing among polymer clusters, the crystallinity of the film could be determined by both types of packing, which is consistent with solution-processed deposition. In techniques like spin-casting, the effect of solvent on the active layer is typically twofold: long time exposure to solvent can either aggregate fullerene-based small organic molecules ${ }^{34}$ or affect the crystallization of the polymer and thus phase separation. ${ }^{35}$ These solvent effects could also impact packing among and within polymer clusters, respectively. From UV-vis absorbance spectra of P3HT films deposited from different primary solvents (Figure $4 \mathrm{c}$ ), it can be seen that the vibrionic peak near $625 \mathrm{~nm}$ is more pronounced for alkyl aromatic solvents that have larger surface roughness, which indicates the polymer chains may be more ordered $^{36,37}$ in larger polymer clusters than in smaller polymer clusters. In addition to UV-vis absorbance, GIWAXS measurements, which have been systematically studied to probe the structure of conjugated polymers, ${ }^{38}$ were also used to characterize the P3HT films. GIWAXS data of P3HT films deposited by emulsion-based RIR-MAPLE (Figure S7, Table S2) show that the stacking of polymer chains in all of the P3HT films has a dominant edge-on orientation. As the polymer cluster size increases due to different primary solvents, the contribution from 
face-on orientation of the polymer chains increases. Different from P3HT films, the UV-vis absorbance spectra for the PCPDTBT films (Figure 4d) show the chlorinated aromatic solvents (plus pseudocumene) yield a more ordered PCPDTBT film due to closer packing between the polymer clusters, indicated by a relative red-shift of the absorbance peak. ${ }^{32,39}$ The exact mechanism by which primary solvents affect polymer packing inside the emulsion droplets is an important topic to be explored in future studies.

Effect of Primary Solvent on Emulsion Droplet Size and Film Properties. From the previous discussion, it is clear that the emulsion droplet size affects the polymer film cluster size and resulting internal morphology. Experimentally, the primary solvent is found to affect the polymer film surface roughness as well. Therefore, the properties of the primary solvents should determine the emulsion droplet size. From Tables 1 and 2, we can draw the conclusion that primary solvents with low solubility-in-water and low vapor pressure usually lead to smooth films and thus should have small droplet sizes in the emulsion. In the following discussion, the effects of primary solvent solubilityin-water and vapor pressure on emulsion droplet size are discussed.

Effect of Primary Solvent: Solubility-in-Water. The solubility-in-water of organic solvents directly relate to the bonding strength between solvent molecules and water molecules. As a result, we propose that the relative bonding strength between solvent molecules to polymer molecules, and solvent molecules to water molecules, determines the solvent droplet size and the polymer cluster size in the emulsion. One challenge to verifying this hypothesis is the difficulty in identifying a parameter to quantify the bonding strength between solvent molecules and polymer molecules. To make a clear illustration, the organic solvents THF, chloroform, and TCB are used as three representative primary solvents to make emulsions for comparison as shown in Figure 5. For these three solvents, the bonding strength to water molecules is highest for THF (solubility-in-water is $30 \mathrm{~g} / 100 \mathrm{~g}$ ), followed by chloroform (solubility-in-water is $0.792 \mathrm{~g} / 100 \mathrm{~g}$ ), and TCB (solubility-inwater is $0.00488 \mathrm{~g} / 100 \mathrm{~g}$ ). Experimentally, when TCB is used as the primary solvent, a very good emulsion is formed and the emulsion is milk-like. In this case, the bonding strength of TCB molecules to PCPDTBT molecules is stronger than the bonding strength of TCB molecules to water molecules (due to the very low solubility-in-water of TCB). The TCB droplets are attracted and repelled by PCPDTBT and water molecules, respectively, preventing coalescence and resulting in a good dispersion in water. However, when chloroform is used as the primary solvent, a poor emulsion is formed such that solvent droplets coalesce very quickly. In this case, the poor emulsion results because the bonding strength of chloroform molecules to water molecules is comparable to the bonding strength of chloroform molecules to PCPDTBT molecules (due to the partial miscibility of chloroform in water indicated by the lower solubility-in-water). The large amount of polymer molecules bond with available chloroform molecules, resulting in larger clusters. In contrast, when THF is used as the primary solvent to make an emulsion, the PCPDTBT directly precipitates out from solution as bulk solid particles. This precipitation of the target polymer occurs because the bonding strength of THF molecules to water molecules is stronger than the bonding strength of THF molecules to PCPDTBT molecules (due to high solubility-inwater of THF). The bonding of THF molecules to water molecules directly exposes the PCPDTBT molecules to the excess amount of water, and the PCPDTBT molecules precipitate out because they cannot bond to water molecules. From this illustration, it can be concluded that the stronger the bonding strength between solvent molecules and polymer molecules, relative to the bonding strength between solvent molecules and water molecules, the smaller the organic solvent droplet size is in the corresponding emulsion. This competition between two bonding strengths is important because it can explain why films deposited from pseudocumene are not smooth despite its low solubility-in-water (i.e., the polymer has poor solubility in the solvent).

Effect of Primary Solvent: Vapor Pressure. Unlike the solubility-in-water, the vapor pressure of the primary solvent does not alter the emulsion droplet size directly. However, it could impact the internal morphology of the film, particularly the amount of trapped solvent and the size of voids in the film. As discussed earlier, the energy from the laser is mainly absorbed by the water-ice matrix, which contains $\mathrm{OH}$ bonds. The primary solvents used in this study do not contain $\mathrm{OH}$ bonds and thus do not directly absorb the laser energy. The water molecules that absorb the laser energy heat up and transfer the heat to the solvent molecules in proximity, which can vaporize the solvent. Although most vaporized solvents are pumped away in the vacuum, a small amount of unvaporized solvent molecules can still be trapped in the deposited film (inside voids between the polymer clusters). On one hand, the trapped solvent molecules could act as charge carrier traps that deteriorate OSC device performance; however, on the other hand, the trapped solvent molecules could help reduce the size of voids by providing a host medium for polymer chains to bridge the voids. Eventually, the trapped solvents are most likely to be removed by the vacuum environment or the annealing process during device fabrication. The importance of the vapor pressure of the solvents is that it describes how easily a solvent can be vaporized and removed from the voids. Solvents with low vapor pressure are easily trapped in polymer films for longer times, acting as traps and helping polymer chains bridge the voids. Provided the trapped solvent molecules are removed eventually, the reduced void size in the film could be beneficial to OSC device performance.

Dissipative Particle Dynamic Simulation. The previous, qualitative discussion of the effects of primary solvent is based on the characterization of deposited films; however, a direct characterization of the emulsion droplets is preferred. Typical measurements of emulsion droplet size, like dynamic light scattering, are not appropriate in this case due to the high polymer concentration and metastable nature of the emulsion targets. While characterization of these complex emulsions using suitable techniques is still under investigation, simulated droplet sizes are provided to help verify the experimental observations. Therefore, dissipative particle dynamics (DPD), a mesoscale simulation technique, was applied to simulate the emulsion droplet size as a function of the solubility-in-water of the primary solvent. DPD has been used successfully to study and predict the phase behavior and properties of emulsification, polymer aggregates, and complex self-assembled structures. ${ }^{40-42}$ All simulation details are provided in the Supporting Information. Briefly, the polymers and surfactant molecules are coarse-grained into DPD polymer beads connected by harmonic spring force; a group of water or primary solvent molecules are coarse-grained into DPD solvent beads. The repulsive parameters for various types of DPD beads represent the affinity between polymers, water, and primary solvents. For example, the repulsive parameter between polymer and water is set to 50, which 
(a) Starting configuration
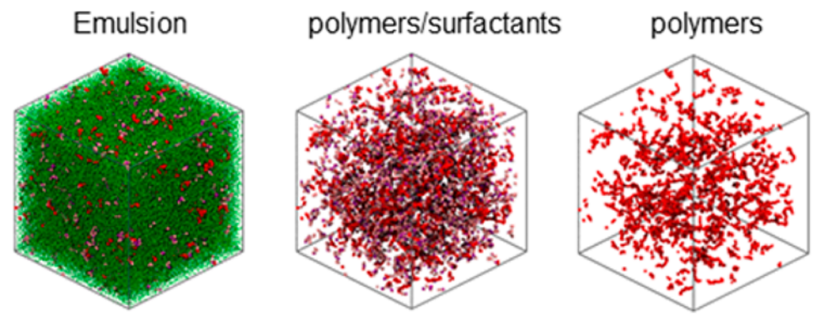

(b) Step 1: in primary solvent Emulsion polymers/surfactants
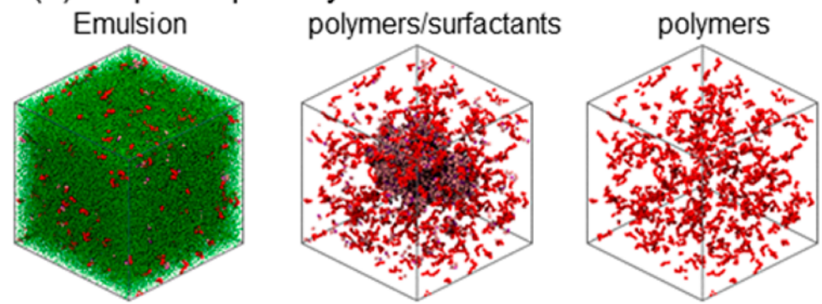

(c) Step 2: in three different primary solvents and water

(c1) primary solvent with high solubility in water $\left(a_{P S-w}=50\right)$ Emulsion polymer/surfactant/ polymers/surfactants polymers
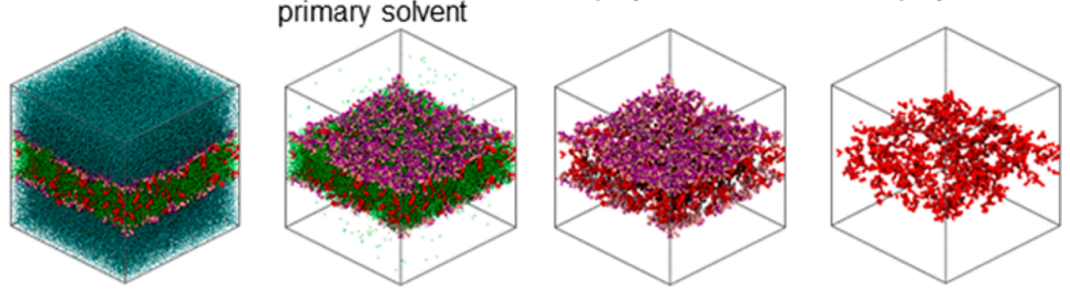

(c2) primary solvent with moderate solubility in water $\left(a_{P S-W}=70\right)$ Emulsion polymer/surfactant/ primary solvent
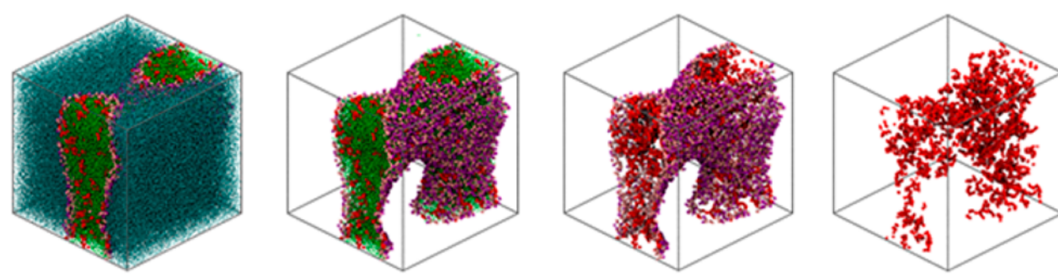

(c3) primary solvent with low solubility in water $\left(a_{P S-w}=90\right)$ Emulsion polymer/surfactant/ polymers/surfactants

polymers
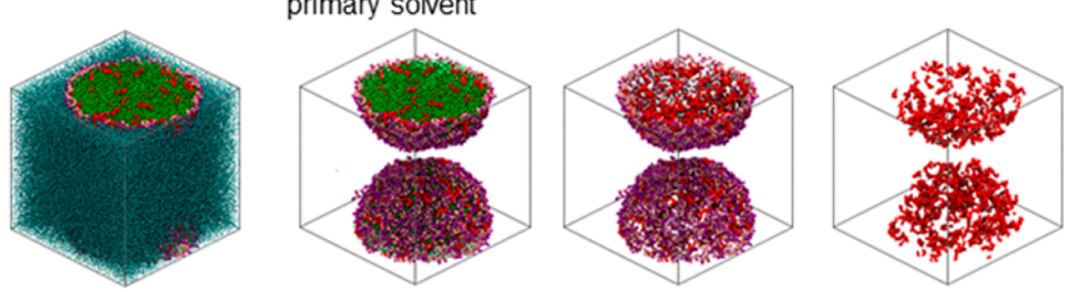

Figure 6. Simulation snapshots of (a) initial and final configurations of (b) step1 and (c) step 2. The red, pink, purple, green, and cyan beads represent the polymer, hydrophobic part in surfactants, hydrophilic part in surfactants, primary solvent, and water, respectively.

indicates the hydrophobic nature of the polymer component. The repulsive parameter between primary solvent and water beads is varied to study the effect of the water solubility of primary solvent on emulsion morphologies. The repulsive parameters between DPD beads are shown in Table S3 of the Supporting Information.

It was observed from simulations that the primary solvent solubility-in-water plays an important role in the morphology of polymer aggregates, as shown in Figure 6. All polymers and surfactants self-assembled into an aggregate, which is formed by a polymer matrix filled with primary solvent and coated with surfactants, for all three cases. Decreasing the solubility of primary solvent in water leads to a morphological transition from membrane to saddle shape and to sphere. The volume ratio for polymer aggregates among three cases is 1:0.944:0.932. It indicates that as the solubility of primary solvent in water 
decreases, smaller and denser polymer aggregates are formed, which agrees with experimental observations.

\section{CONCLUSION}

In summary, the effects of primary solvent on the properties of conjugated polymer films deposited by emulsion-based RIRMAPLE are studied, which provides great insight into the film formation process during the deposition. It is found that polymer films are deposited by the discrete stacking of polymer clusters. While the stacking between polymer clusters mainly determines the surface roughness and formation of internal voids in the film, the stacking of polymer chains inside the cluster determines the order of the film. In addition, the size of the polymer cluster is determined by the solvent droplet size in the emulsion, which is governed by the relative bonding strength of the primary solvent molecules to water molecules and to polymer molecules. Therefore, the primary solvent has a great impact on the surface roughness and internal morphology of the deposited polymer films, which is further demonstrated by different polymer-based OSC device performance fabricated using different primary solvents in RIR-MAPLE. This study offers a fundamental understanding of how the properties of primary solvents in the emulsion target translate into thin film properties and solar cell performance, which encourages further studies on how other properties of the emulsion target (e.g., type of emulsion, surfactant, secondary solvent) can be used to design the properties of different polymer films (e.g., amphiphilic, hydrophilic polymers) using the emulsion-based RIR-MAPLE technique.

\section{METHODS}

Materials. PCPDTBT $\left(M_{\mathrm{w}}=30 \mathrm{kDa}\right)$ and P3HT $\left(M_{\mathrm{w}}=70 \mathrm{kDa}\right)$ were purchased from Solaris Chem Inc. PCBM (99.5\% purity) and $\mathrm{PC}_{71} \mathrm{BM}$ (99\% purity) were purchased from American Dye Source, Inc. PEDOT:PSS (Clevios PVP AI 4083) was purchased from Clevios. Toluene, $o$-xylene, pseudocumene, chlorobenzene, $o$-dichlorobenzene, 1,2,4-trichlorobenzene, phenol, and sodium dodecyl sulfate (SDS) were purchased from Sigma-Aldrich. The solar cell encapsulation epoxy was purchased from Ossila Ltd. Custom patterned ITO-coated glass substrates were purchased from Xin Yan Technology (Hong Kong). All materials were used as-received without further purification.

$\mathrm{TiO}_{x}$ Synthesis. $\mathrm{TiO}_{x}$ synthesis followed previous reported procedures with slight modification. ${ }^{43} 0.75 \mathrm{~mL}$ of titanium(IV) isopropoxide, $3 \mathrm{~mL}$ of methoxyethanol, and $0.3 \mathrm{~mL}$ of ethanolamine were injected into a three-necked flask one by one at room temperature. The three-necked flask must be under continuous nitrogen flow, and the starting materials must be injected in the order. The mixed solution was stirred at room temperature for $1 \mathrm{~h}$. Then the mixed solution was heat at $80^{\circ} \mathrm{C}$ for an hour and $120^{\circ} \mathrm{C}$ for another hour. During the heating, the starting clear solution turned into a low density gel with dark wine color. After the solution cooling to room temperature, $1.5 \mathrm{~mL}$ of methanol was injected into the flask to extract final semitransparent $\mathrm{TiO}_{x}$ sol-gel product. The final product was further diluted by 1:200 in methanol, and the resulting diluted $\mathrm{TiO}_{x}$ sol-gel solution was used for spin-casting.

Emulsion Target Preparation. The emulsion target for RIRMAPLE deposition consists primary solvent, secondary solvent, and deionized (DI) water containing surfactant sodium dodecyl sulfate (SDS). The $0.001 \mathrm{wt} \%$ SDS was prepared in DI water in advance. Heated phenol was used as the secondary solvent in all emulsions. To prepare emulsion solution, $5 \mathrm{mg}$ of polymer was first dissolved into selected primary solvents completely. Then the heated phenol solution was added into the prepared polymer solution. Reheat the mixed solution until the polymer completely dissolve into the solution again. At last, DI water containing SDS was added into the mixed solution to make emulsion. The volume ratio between primary solvents, phenol, and DI water is 1:0.25:3, and a total $6 \mathrm{~mL}$ emulsion was prepared as the target solution.

RIR-MAPLE Deposition of Polymer and Blended Films. For polymer (P3HT, PCPDTBT) films deposition, the prepared emulsion was injected into the chilled target holder using a syringe $\left(-190{ }^{\circ} \mathrm{C}\right.$, cooled by liquid nitrogen). Every time, only $0.5 \mathrm{~mL}$ emulsion was injected to the chili target to make sure the emulsion was frozen into a solid ice instantly (less than $5 \mathrm{~s}$ ) without any notable phase separation. In total, $6 \mathrm{~mL}$ of emulsion was injected to chili target to ensure enough material for the deposition. For blended film (P3HT:PCBM, PCPDTBT:PC ${ }_{71} \mathrm{BM}$ ) film deposition. The emulsion of polymer and small organic molecules ( $\mathrm{PCBM}$ and $\mathrm{PC}_{71} \mathrm{BM}$ ) were prepared separately. The target holder was partitioned, and one section was injected with the polymer emulsion while the remaining section was injected with the small organic molecules emulsion. The blended ratio is determined by the target partition ratio, which is $1.5: 1$ and $1: 1.5$ for P3HT:PCBM and PCPDTBT:PC ${ }_{71} B M$, respectively. The deposition temperature at substrate was not actively controlled and dropped from room temperature to $5-6{ }^{\circ} \mathrm{C}$ in the course of deposition because the generated plume from the icy target cools down the substrate. For all depositions, the laser fluence is $1.8 \mathrm{~J} / \mathrm{cm}^{2}$ per pulse at $2 \mathrm{~Hz}$ repetition rate, and the substrate to target distance is $7 \mathrm{~cm}$. The deposition rate is mainly determined by the target concentration and is roughly $20-25$ $\mathrm{nm} / \mathrm{h}$ when the target concentration is $5 \mathrm{mg} / \mathrm{mL}$ in primary solvent using the target preparation method described above.

Organic Solar Cells Fabrication. Prepatterned ITO-coated glass slides were used as anode which were ultrasonically cleaned, sequentially, with acetone, methanol, and isopropyl alcohol. $5 \mathrm{~min}$ oxygen plasma treatment was performed to make ITO more hydrophilic and improve subsequent PEDOT:PSS film quality. The PEDOT:PSS, a hole transport layer, was spin-coated at $4000 \mathrm{rpm}$ for $30 \mathrm{~s}$ and baked at $150{ }^{\circ} \mathrm{C}$ for $10 \mathrm{~min}$ in air. The active layer was deposited by emulsionbased RIR-MAPLE as described. The thickness of P3HT:PCBM was controlled as roughly $120 \mathrm{~nm}$ while PCPDTBT:PC ${ }_{71} \mathrm{BM}$ was controlled as roughly $100 \mathrm{~nm}$. $\mathrm{TiO}_{x}$ sol-gel solution was then spin-cast on top of the active layer at $3000 \mathrm{rpm}$ for $30 \mathrm{~s}$. To dry the $\mathrm{TiO}_{x}$ film, the film was annealed at 70 and $140{ }^{\circ} \mathrm{C}$ for the P3HT:PCBM and PCPDTBT:PC ${ }_{71} \mathrm{BM}$ system, respectively, for $5 \mathrm{~min}$ in the air. For the P3HT:PCBM system, another thermal annealing at $140{ }^{\circ} \mathrm{C}$ for $10 \mathrm{~min}$ was performed in the glovebox to improve the film morphology. Finally, an aluminum cathode $(120 \mathrm{~nm})$ was thermally evaporated $\left(1 \times 10^{-6}\right.$ Torr) on top, defining a $9 \mathrm{~mm}^{2}$ active area. All of the OSCs were encapsulated using encapsulation epoxy (Ossila, Ltd.) before measurement in ambient atmosphere under simulated AM 1.5G illumination $\left(100 \mathrm{~mW} / \mathrm{cm}^{2}\right)$. All devices were stored in a vacuum box before encapsulation and characterization.

Thin Film Characterization. AFM height images were obtained using a Veeco 3100 Dimension microscope in a tapping mode. Crosssectional SEM images was obtained using an FEI XL30 SEM. Before imaging, the surface of the film is coated with a thin layer $(\sim 5 \mathrm{~nm})$ of gold to prevent charging effect. UV-vis absorption spectra were obtained using a Shimadzu UV-3600 spectrophotometer. J-V measurements were completed using a Keithley Instruments 4200-SCS semiconductor analyzer. A solar simulator (Abet Technologies, model 10500) was set to 1 sun equivalent output irradiance by using a calibrated reference silicon cell (Oriel, model 91150). The EQE measurement were taken on an Oriel monochromator-based EQE system with a $500 \mathrm{~W}$ Xe light source in ac mode. GIWAXS measurements were conducted using a SAXSLab Ganesha system to provide structural information about polymer orientation and crystallinity in films deposited by emulsion-based RIR-MAPLE. The GIWAXS technique involves irradiating the films in a reflection configuration at grazing incidence with a $\mathrm{Cu} \mathrm{K} \alpha \mathrm{X}$-ray point source and collecting the scattering profile on a two-dimensional detector.

Simulation Method. All simulations were performed using dissipative particle dynamics (DPD) via LAMMPS. ${ }^{44,45}$ DPD is a coarse-grained simulation technique in which one DPD bead represents a group of atoms or a volume of fluid. ${ }^{46,47} \mathrm{DPD}$ simulations started from a random dispersion of 350 polymers with length of 20 -mer and 1400 amphiphilic chains consisting of a 6-mer hydrophobic block and 2-mer 
hydrophilic block in the solution (Figure 6). The total number of beads in the system was 139968 . In the first stage of simulation, the rest of the box was filled with primary solvent beads (Figure 6). In the second stage of simulation, a fraction of 3.25/4.25 of primary solvent beads turn into was replaced by water beads. To match experiment. The small fraction of phenol present in experiment is omitted. A considerably long simulation ( $\geq 2000000$ steps) was conducted for each stage to get thermodynamic equilibrium. A cubic simulation box $(36 \times 36 \times 36)$ was applied with periodic boundary condition in three directions.

\section{ASSOCIATED CONTENT}

\section{S Supporting Information}

The Supporting Information is available free of charge on the ACS Publications website at DOI: 10.1021/acsami.6b05596.

AFM and SEM images of PCPDTBT films deposited from different primary solvents, SEM images of P3HT films deposited from different primary solvents, AFM images of PCPDTBT, $\mathrm{PC}_{71} \mathrm{BM}$, and blended PCPDTBT/PC $\mathrm{P}_{71} \mathrm{BM}$ deposited from $o$-DCB, AFM images of $\mathrm{PC}_{71} \mathrm{BM}$ films deposited from different primary solvents, UV-vis absorption of PCPDTBT films and $J-V$ curve of PCPDTBT:PC ${ }_{71} \mathrm{BM}$ solar cells deposited by RIRMAPLE with and without solvent additive, GIWAXS 1D plot and table of P3HT films deposited from different primary solvents, CR-AFM measurment of PCPDTBT films deposited from different primary solvents, DPD simulation details (PDF)

\section{AUTHOR INFORMATION}

\section{Corresponding Author}

*E-mail: adrienne.stiffroberts@duke.edu (A.D.S.-R.).

\section{Notes}

The authors declare no competing financial interest.

\section{ACKNOWLEDGMENTS}

This work was supported by the NSF's Research Triangle MRSEC (DMR-1121107) and the Office of Naval Research (N00014-10-1-0481). We acknowledge Qing Tu from Duke University for his help of acoustic AFM measurement.

\section{REFERENCES}

(1) Caricato, A. P.; Cesaria, M.; Gigli, G.; Loiudice, A.; Luches, A.; Martino, M.; Resta, V.; Rizzo, A.; Taurino, A. Poly-(3-hexylthiophene)/ $[6,6]$-phenyl-C61-butyric-acid-methyl-ester Bilayer Deposition by Matrix-assisted Pulsed Laser Evaporation for Organic Photovoltaic Applications. Appl. Phys. Lett. 2012, 100, 073306.

(2) Facchetti, A. Pi-Conjugated Polymers for Organic Electronics and Photovoltaic Cell Applications. Chem. Mater. 2011, 23, 733-758.

(3) Hide, F.; DiazGarcia, M. A.; Schwartz, B. J.; Heeger, A. J. New Developments in the Photonic Applications of Conjugated Polymers. Acc. Chem. Res. 1997, 30, 430-436.

(4) McGehee, M. D.; Heeger, A. J. Semiconducting (Conjugated) Polymers as Materials for Solid-State Lasers. Adv. Mater. 2000, 12, $1655-1668$

(5) Gunes, S.; Neugebauer, H.; Sariciftci, N. S. Conjugated Polymerbased Organic Solar Cells. Chem. Rev. 2007, 107, 1324-1338.

(6) Krebs, F. C. Fabrication and processing of polymer solar cells: A Review of Printing and Coating Techniques. Sol. Energy Mater. Sol. Cells 2009, 93, 394-412.

(7) Fujii, Y.; Atarashi, H.; Hino, M.; Nagamura, T.; Tanaka, K. Interfacial Width in Polymer Bilayer Films Prepared by Double-spincoating and Flotation Methods. ACS Appl. Mater. Interfaces 2009, 1, $1856-1859$.
(8) Usui, H. Preparation of Polymer Thin Films by Physical Vapor Deposition. In Functional Polymer Films; Wiley-VCH Verlag GmbH \& Co. KGaA: 2011; pp 287-318.

(9) Usui, H. Formation of Polymer Thin Films and Interface Control by Physical Vapor Deposition. Proc. SPIE 2009, 7404, 74040E.

(10) Thejo Kalyani, N.; Dhoble, S. J. Organic Light Emitting Diodes: Energy Saving Lighting Technology-A Review. Renewable Sustainable Energy Rev. 2012, 16, 2696-2723.

(11) Pique, A. The Matrix-Assisted Pulsed Laser Evaporation (MAPLE) Process: Origins and Future Directions. Appl. Phys. A: Mater. Sci. Process. 2011, 105, 517-528.

(12) Chrisey, D. B.; Pique, A.; McGill, R. A.; Horwitz, J. S.; Ringeisen, B. R.; Bubb, D. M.; Wu, P. K. Laser Deposition of Polymer and Biomaterial Films. Chem. Rev. 2003, 103, 553-576.

(13) Mercado, A. L.; Allmond, C. E.; Hoekstra, J. G.; Fitz-Gerald, J. M. Pulsed Laser Deposition vs. Matrix Assisted Pulsed Laser Evaporation for Growth of Biodegradable Polymer Thin Films. Appl. Phys. A: Mater. Sci. Process. 2005, 81, 591-599.

(14) Srinivasan, R.; Maynebanton, V. Self-Developing Photoetching of Poly(Ethylene-Terephthalate) Films by Far Ultraviolet Excimer LaserRadiation. Appl. Phys. Lett. 1982, 41 (6), 576-578.

(15) Pate, R.; McCormick, R.; Chen, L.; Zhou, W.; Stiff-Roberts, A. D. RIR-MAPLE Deposition of Conjugated Polymers for Application to Optoelectronic Devices. Appl. Phys. A: Mater. Sci. Process. 2011, 105, 555-563.

(16) Pate, R.; Stiff-Roberts, A. D. The impact of Laser-target Absorption Depth on the Surface and Internal Morphology of Matrixassisted Pulsed Laser Evaporated Conjugated Polymer Thin Films. Chem. Phys. Lett. 2009, 477, 406-410.

(17) McCormick, R. D.; Lenhardt, J.; Stiff-Roberts, A. D. Effects of Emulsion-Based Resonant Infrared Matrix Assisted Pulsed Laser Evaporation (RIR-MAPLE) on the Molecular Weight of Polymers. Polymers (Basel, Switz.) 2012, 4, 341-354.

(18) Ge, W. Y.; McCormick, R. D.; Nyikayaramba, G.; Stiff-Roberts, A. D. Bulk Heterojunction PCPDTBT:PC71BM Organic Solar Cells Deposited by Emulsion-based, Resonant Infrared Matrix-assisted Pulsed Laser Evaporation. Appl. Phys. Lett. 2014, 104, 223901.

(19) Ge, W. Y.; Atewologun, A.; Stiff-Roberts, A. D. Hybrid Nanocomposite Thin Films deposited by Emulsion-based Resonant Infrared Matrix-assisted Pulsed Laser Evaporation for Photovoltaic Applications. Org. Electron. 2015, 22, 98-107.

(20) McCormick, R. D.; Cline, E. D.; Chadha, A. S.; Zhou, W. D.; StiffRoberts, A. D. Tuning the Refractive Index of Homopolymer Blends by Controlling Nanoscale Domain Size via RIR-MAPLE Deposition. Macromol. Chem. Phys. 2013, 214, 2643-2650.

(21) Ge, W.; Yu, Q.; Lopez, G. P.; Stiff-Roberts, A. D. Antimicrobial Oligo(p-phenylene-ethynylene) Film Deposited by Resonant Infrared Matrix-assisted Pulsed Laser Evaporation. Colloids Surf., B 2014, 116, $786-792$.

(22) Yu, Q.; Ge, W.; Atewologun, A.; Lopez, G. P.; Stiff-Roberts, A. D. RIR-MAPLE Deposition of Multifunctional Films Combining Biocidal and Fouling Release Properties. J. Mater. Chem. B 2014, 2, 4371-4378. (23) Lantz, K. R.; Pate, R; Stiff-Roberts, A. D.; Duffell, A. G.; Smith, E. R.; Everitt, H. O. Comparison of Conjugated Polymer Deposition Techniques by Photoluminescence Spectroscopy. J. Vac. Sci. Technol. B 2009, 27, 2227-2231.

(24) Schwartz, B. J. Conjugated Polymers as Molecular Materials: How Chain Conformation and Film Morphology Influence Energy Transfer and Interchain Interactions. Annu. Rev. Phys. Chem. 2003, 54, 141-172. (25) http://murov.info/orgsolvents.htm.

(26) Leveugle, E.; Sellinger, A.; Fitz-Gerald, J. M.; Zhigilei, L. V. Making Molecular Balloons in Laser-induced Explosive Boiling of Polymer Solutions. Phys. Rev. Lett. 2007, 98, 216101.

(27) Sellinger, A.; Leveugle, E.; Fitz-Gerald, J. M.; Zhigilei, L. V. Generation of Surface Features in Films Deposited by Matrix-assisted Pulsed Laser Evaporation: the Effects of the Stress Confinement and Droplet Landing Velocity. Appl. Phys. A: Mater. Sci. Process. 2008, 92, 821-829. 
(28) Shepard, K. B.; Guo, Y. L.; Arnold, C. B.; Priestley, R. D. Nanostructured Morphology of Polymer Films Prepared by Matrix Assisted Pulsed Laser Evaporation. Appl. Phys. A: Mater. Sci. Process. 2013, 110, 771-777.

(29) Fryček, R.; Jelínek, M.; Kocourek, T.; Fitl, P.; Vrňata, M.; Myslík, V.; Vrbová, M. Thin Organic Layers Prepared by MAPLE for Gas Sensor Application. Thin Solid Films 2006, 495, 308-311.

(30) Kim, J. Y.; Kim, S. H.; Lee, H. H.; Lee, K.; Ma, W. L.; Gong, X.; Heeger, A. J. New Architecture for High-efficiency Polymer Photovoltaic Cells using Solution-based Titanium Oxide as an Optical Spacer. Adv. Mater. 2006, 18, 572-576.

(31) Ge, W.; McCormick, R. D.; Nyikayaramba, G.; Stiff-Roberts, A. D. Bulk Heterojunction PCPDTBT: PC71BM Organic Solar Cells Deposited by Emulsion-based, Resonant Infrared Matrix-assisted Pulsed Laser Evaporation. Appl. Phys. Lett. 2014, 104, 223901.

(32) Peet, J.; Kim, J. Y.; Coates, N. E.; Ma, W. L.; Moses, D.; Heeger, A. J.; Bazan, G. C. Efficiency Enhancement in Low-bandgap Polymer Solar Cells by Processing with Alkane Dithiols. Nat. Mater. 2007, 6, 497-500.

(33) Agostinelli, T.; Ferenczi, T. A. M.; Pires, E.; Foster, S.; Maurano, A.; Müller, C.; Ballantyne, A.; Hampton, M.; Lilliu, S.; Campoy-Quiles, M.; Azimi, H.; Morana, M.; Bradley, D. D. C.; Durrant, J.; Macdonald, J. E.; Stingelin, N.; Nelson, J. The Role of Alkane Dithiols in Controlling Polymer Crystallization in Small Band Gap Polymer:Fullerene Solar Cells. J. Polym. Sci., Part B: Polym. Phys. 2011, 49, 717-724.

(34) Wang, W.; Guo, S.; Herzig, E. M.; Sarkar, K.; Schindler, M.; Magerl, D.; Philipp, M.; Perlich, J.; Müller-Buschbaum, P. Investigation of Morphological Degradation of P3HT:PCBM Bulk Heterojunction Films Exposed to Long-term Host Solvent Vapor. J. Mater. Chem. A 2016, 4, 3743-3753.

(35) Ruderer, M. A.; Guo, S.; Meier, R.; Chiang, H.-Y.; Körstgens, V.; Wiedersich, J.; Perlich, J.; Roth, S. V.; Müller-Buschbaum, P. SolventInduced Morphology in Polymer-Based Systems for Organic Photovoltaics. Adv. Funct. Mater. 2011, 21, 3382-3391.

(36) Li, G.; Shrotriya, V.; Huang, J. S.; Yao, Y.; Moriarty, T.; Emery, K.; Yang, Y. High-efficiency Solution Processable Polymer Photovoltaic Cells by Self-organization of Polymer Blends. Nat. Mater. 2005, 4 (11), 864-868.

(37) Chu, C. W.; Yang, H. C.; Hou, W. J.; Huang, J. S.; Li, G.; Yang, Y. Control of the Nanoscale Crystallinity and Phase Separation in Polymer Solar Cells. Appl. Phys. Lett. 2008, 92, 103306.

(38) Muller-Buschbaum, P. The Active Layer Morphology of Organic Solar Cells Probed with Grazing Incidence Scattering Techniques. Adv. Mater. 2014, 26, 7692-7709.

(39) Albrecht, S.; Schafer, S.; Lange, I.; Yilmaz, S.; Dumsch, I.; Allard, S.; Scherf, U.; Hertwig, A.; Neher, D. Light Management in PCPDTBT:PC70BM Solar Cells: A Comparison of Standard and Inverted Device Structures. Org. Electron. 2012, 13, 615-622.

(40) Li, N. K.; Fuss, W. H.; Yingling, Y. G. An Implicit Solvent Ionic Strength (ISIS) Method to Model Polyelectrolyte Systems with Dissipative Particle Dynamics. Macromol. Theory Simul. 2015, 24, 7-12.

(41) Li, N. K.; Fuss, W. H.; Tang, L.; Gu, R.; Chilkoti, A.; Zauscher, S.; Yingling, Y. G. Prediction of Solvent-induced Morphological Changes of Polyelectrolyte Diblock Copolymer Micelles. Soft Matter 2015, 11, 8236-8245.

(42) Li, Y.; Zhang, H.; Bao, M.; Chen, Q. Aggregation Behavior of Surfactants with Different Molecular Structures in Aqueous Solution: DPD Simulation Study. J. Dispersion Sci. Technol. 2012, 33, 1437-1443.

(43) Cho, S.; Lee, K.; Heeger, A. J. Extended Lifetime of Organic FieldEffect Transistors Encapsulated with Titanium Sub-Oxide as an 'Active' Passivation/Barrier Layer. Adv. Mater. 2009, 21, 1941-1944.

(44) http://lammps.sandia.gov.

(45) Plimpton, S. Fast Parallel Algorithms for Short-Range MolecularDynamics. J. Comput. Phys. 1995, 117, 1-19.

(46) Hoogerbrugge, P. J.; Koelman, J. M. V. A. Simulating Microscopic Hydrodynamic Phenomena with Dissipative Particle Dynamics. Europhys. Lett. 1992, 19, 155-160.

(47) Groot, R. D.; Warren, P. B. Dissipative Particle Dynamics: Bridging the Gap between Atomistic and Mesoscopic Simulation. J. Chem. Phys. 1997, 107, 4423-4435. 